\title{
QUANTIFICAÇÃO DA DINÂMICA DOS REMANESCENTES FLORESTAIS NO MUNICÍPIO DE JAQUIRANA, RS, EM IMAGENS DE SATÉLITE ${ }^{1}$
}

\author{
Maria do Carmo Lima e Cunha ${ }^{2}$, Michele Monguilhott ${ }^{3}$, Dejanira Luderitz Saldanha², Laurindo Antonio
} Guasselli $^{2}$ e Gabriel de Oliveira ${ }^{4}$

\begin{abstract}
RESUMO - Técnicas de sensoriamento remoto e de geoprocessamento foram usadas com o objetivo de avaliar a dinâmica da cobertura vegetal, mais especificamente das classes Floresta Ombrófila Mista e Silvicultura, no Município de Jaquirana, Nordeste do Rio Grande do Sul, entre os anos de 2002 e 2007. Os resultados revelaram significativo aumento da silvicultura em detrimento da cobertura florestal natural nesse curto espaço de tempo. A perda da mata natural pertencente à classe de Floresta Ombrófila Mista no município foi de 5.643,37 ha no espaço de cinco anos. No entanto, a silvicultura que ocupava 921,10 ha em 2002 passou a ocupar 4.814,37 em 2007. Foi observado também que extensas faixas ao longo das margens dos rios Antas, Tainhas e Camisas que permeiam a região estão ocupadas por plantações de Pinus sp.
\end{abstract}

Palavras-chave: Geoprocessamento, Floresta Ombrófila Mista e Silvicultura.

\section{QUANTIFICATION OF FOREST REMNANT DYNAMICS IN JAQUIRANA, RS, IN SATELLITE IMAGES}

\begin{abstract}
Techniques of remote sensing and geoprocessing were used to evaluate the dynamics of the vegetal cover, more specifically in Mixed Ombrophile Forest (Araucaria Forest) and Forestry classes in the Jaquirana, northeastern Rio Grande do Sul, from 2002 to 2007. The results showed a significant increase of forestry in detriment to natural forest covering in this short time period. The loss of the natural wood belonging to Mixed Ombrophile Forest was of 5,643.37 ha in a five-year period of time. On the other hand, the forestry area which was 921.10 ha in 2002, increased to 4,814.37 ha in 2007. It was also observed that large areas along the banks of the rivers Antas, Tainhas, and Camisas are now occupied by Pinus sp. crops.
\end{abstract}

Keywords: Geoprocessing, Ombrophilous mixed forest and Silviculture.

\section{INTRODUÇÃO}

Na região Nordeste do Rio Grande do Sul, plantios de espécies exóticas para fins industriais têm-se expandido rapidamente nas últimas décadas, resultando em mudanças no uso da terra e alterações na cobertura vegetal natural.

A forte redução de ecossistemas naturais, quase sempre acompanhadas por perturbações de diferentes naturezas resulta da perda das diversidades vegetal e animal. Essas perturbações podem estar ligadas a aspectos de cunho econômico, crescimento populacional, especulação imobiliária, avanço das áreas de ocupação agrícola e até mesmo o reflorestamento por espécies exóticas como Pinus e Eucalipto, ocasionando diversos problemas relacionados à gestão e monitoramento dessas formações florestais (VIANNA et al., 1992).

O Estado do Rio Grande do Sul, assim como no restante do país, foi profundamente alterado no que se refere ao Bioma Mata Atlântica (MARCUZZO et

\footnotetext{
${ }^{1}$ Recebido em 26.08.2009 e aceito para publicação em 20.04.2011.

${ }^{2}$ Universidade Federal do Rio Grande do Sul, UFRGS, Brasil. E-mail: <maria.cunha@ufrgs.br>, <dejanira.saldanha@ufrgs.br> e <laurindo.guasselli@ufrgs.br>.

${ }^{3}$ Universidade Federal de Santa Maria, UFSM,Brasil. E-mail: <michelegads@yahoo.com.br>.

${ }^{4}$ Instituto Nacional de Pesquisas Espaciais, INPE, Brasil. E-mail: <gabrieloliveira13@hotmail.com>.
} 
al., 1998). Segundo dados da Fundação SOS Mata Atlântica/INPE de 2008, o domínio da Mata Atlântica ocupa $13.352,71$ ha, o que representa $47 \%$ do estado, permanecendo hoje apenas 3,39\% dessa área coberta por remanescentes florestais naturais.

Dados recentes (GUASSELLI et al., 2009), obtidos por análise temporal a partir de imagens SPOT, dos anos de 2002 e 2007, revelaram um decremento de 11,88\% no total de área coberta por remanescentes do bioma Mata Atlântica no Planalto Meridional do RS, onde se destacam as formações Floresta Ombrófila Mista (Mata de Araucária), Floresta Estacional Semidecidual e Formações Florestais Secundárias, além da Estepe Gramíneo Lenhosa.

O mapeamento de fragmentos florestais é, assim, de extrema importância para diversas informações que possibilitem possíveis planos de conservação, como a implantação de corredores ecológicos, que são essenciais no controle de fluxos biológicos na paisagem, reduzindo os riscos de extinção local e favorecendo recolonizações (METZGER, 2003).

Na região Nordeste do Rio Grande do Sul, mais precisamente no Município de Jaquirana, área objeto deste estudo, a vegetação nativa dominante é representada pela Floresta Ombrófila Mista e pelos Campos de Cima da Serra (Estepe Gramíneo-lenhosa), cuja ocorrência, por vezes, se dá na forma de maciços florestais interdigitados com as formações campestres. Núcleos de Mata Secundária, representados por arvoretas em estágio médio a avançado de crescimento, também são comuns. Extensas áreas de cultivos de exóticas (com predomínio de Pinus sp.) formam mosaicos compostos por matas naturais, campos, mata secundária e silvicultura.

\section{MATERIAL E MÉTODOS}

O Município de Jaquirana está localizado no extremo Nordeste do RS (Figura 1), na região geomorfológica denominada “Campos de Cima da Serra”, a uma altitude média de $920 \mathrm{~m}$. Sua fisiografia se caracteriza por uma planície elevada, de relevo suave e com recortes profundos de origem erosiva fluvial. O substrato, de origem vulcânica, é de composição riodacítica a riolítica (ROISENBERG; VIERO, 2000), originando solos imaturos.

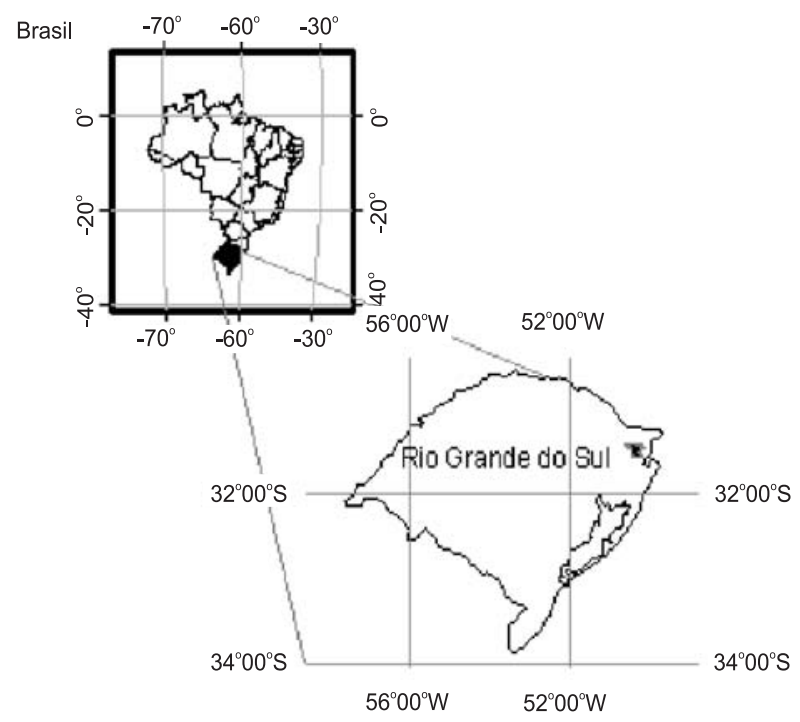

Figura 1 - Mapa de localização do Município de Jaquirana, Rio Grande do Sul.

Figure 1 - Localization map of the muncipality of Jaquirana, Rio Grande do Sul.

Para avaliar a evolução da distribuição espacial da vegetação natural e da silvicultura ocorrente nesse município, no período compreendido entre os anos de 2002 e 2007, foram analisadas imagens de satélite através do sistema ArcGis. A aplicação desse sistema que permite a análise espacial de dados georreferenciados e a geração de mapas utilizados para diagnósticos e prognósticos de determinado contexto ambiental (SOUZA et al., 2006) teve como objetivo quantificar os remanescentes florestais naturais em relação à expansão da silvicultura praticada na região, no período citado.

A extração das informações relativas aos fragmentos florestais resultou do processamento de duas cenas (60 km x $60 \mathrm{~km}$ ) correspondentes a imagens multiespectrais datadas de 2002 e 2007, obtidas pelo sensor HRG, SPOT 5 , georreferenciadas com base no Datum WGS84, nas quatro bandas espectrais (regiões espectrais do visível, infravermelho próximo e infravermelho de ondas curtas), com resolução espacial de 10 m e classificadas pelo algoritmo Máxima Verossimilhança. As cenas foram recortadas para a análise das classes de vegetação, conforme a cartografia básica brasileira do DSG, na escala 1:50.000, projeção UTM (Transversa Universal de Mercator), tendo sido o processamento realizado nos Laboratórios do Centro Estadual de Pesquisa em 
Sensoriamento Remoto e Meteorologia do RS - CEPSRM, da Universidade Federal do Rio Grande do Sul (SALDANHA et al., 2008).

O software ARCGIS 9.0 foi usado para extração e processamento de informações compiladas de arquivos em escala 1:50.000 do Projeto Conservação da Mata Atlântica -PCMA, visando à distribuição espacial da floresta natural e de silvicultura dos anos de 2002 e 2007. Além disso, foram identificadas áreas ambientalmente frágeis, suscetíveis à ação erosiva, ao longo dos principais rios que permeiam o Município de Jaquirana. Os dados relativos à rede hídrica da região foram extraídos da base georreferenciada da FEPAM em escala 1:250.000, ajustados à imagem do sensor HRG.

A análise espacial da cobertura vegetal foi realizada a partir da elaboração de mapas básicos com a definição do limite da área do estudo e compilação de bases existentes para ajustes à imagem SPOT. Após a espacialização desses dados, foram gerados mapas das áreas de silvicultura e de mata natural, além de um mapa de pontos críticos para a vegetação natural. Os dados resultantes foram digitalizados e transformados em produtos temáticos. Todo processamento foi realizado no LAGEO do Instituto de Geociências da UFRGS.

Embora na área de estudo também ocorram matas nativas representativas das classes de Floresta Estacional e de Floresta Ombrófila Densa, optou-se por enfocar este estudo na análise da Mata de Araucária, visto ser seu perfil, na região, distinto das demais classes de mata pela ausência de uma associação significativa com a agricultura, resultando em manchas originais, ainda que impactadas pela extração de madeiras de lei.

Na classe Floresta Ombrófila Mista foram agrupados os polígonos identificados como aglomerados arbóreos contendo 100 ou mais pixels.

Para delimitar áreas ambientalmente frágeis ao longo das margens dos principais rios que percorrem o Município de Jaquirana, foram produzidos buffers, feições que representam distância uniforme em torno de determinada classe, através da análise de proximidade por área de influência. Nos rios das Antas e Tainhas, com leitos entre 100 e 120 m de largura máxima, foram consideradas faixas marginais (buffers) fixas de $100 \mathrm{~m}$, enquanto no Rio Camisas com largura de $50 \mathrm{~m}$ foi considerada a faixa de $50 \mathrm{~m}$.

\section{RESULTADOS E DISCUSSÃO}

A partir do aplicativo ArcMap foram gerados mapasbase, limitados às cenas da imagem SPOT, em formato shapefile, das classes de Silvicultura (FL) e de Floresta Ombrófila Mista (MOM), com a representação da distribuição espacial de ambas nos anos de 2002 e 2007 (Figuras 2 e 3).

No percurso dos rios das Antas, Tainhas e Camisas, através da análise de proximidade por área de influência, foram também delimitados pontos críticos relacionados ao plantio de Pinus sp. em locais muito próximos às
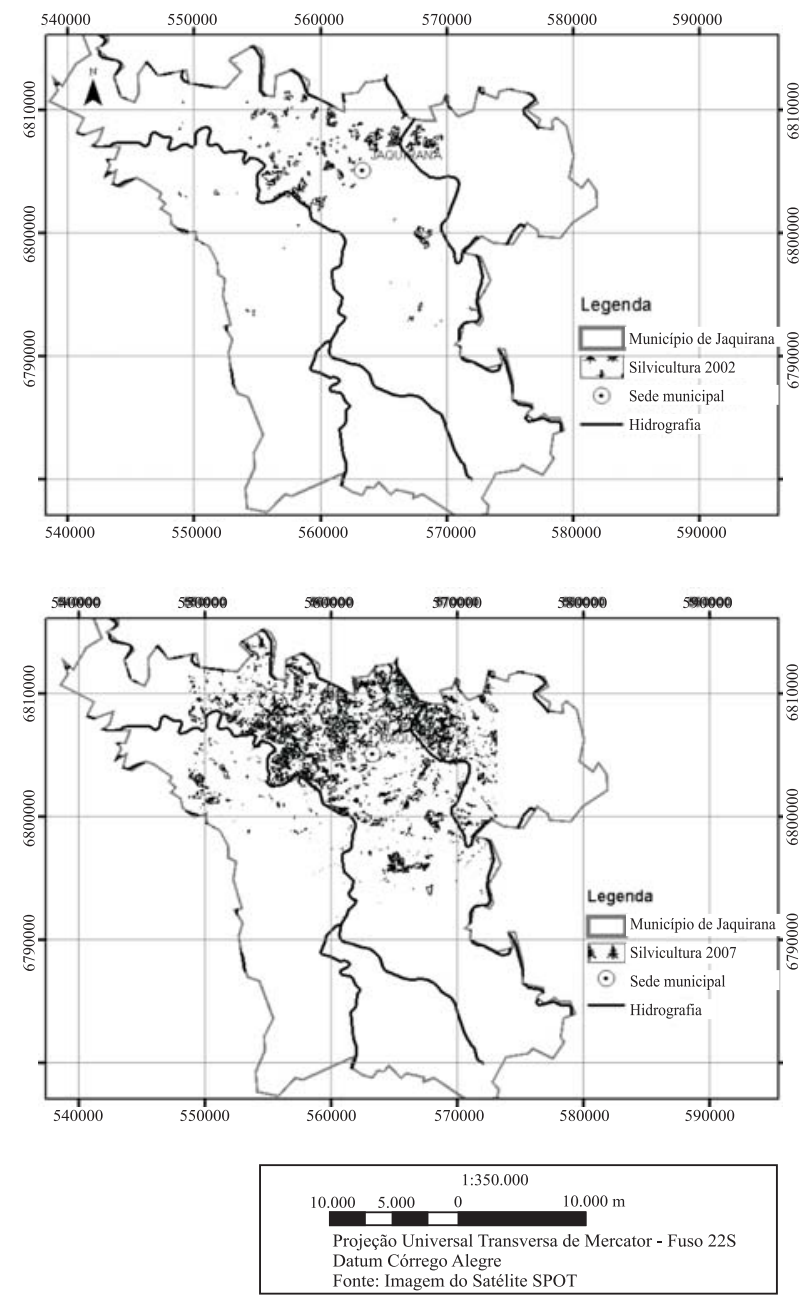

Figura 2 - Distribuição da Classe de Silvicultura no município de Jaquirana nos anos de 2002 (acima) e 2007 (abaixo).

Figure 2 - Distribution of Silviculture Class in the municipality of Jaquirana from 2002 (above)to 2007 (below).

Revista Árvore, Viçosa-MG, v.35, n.4, p.867-873, 2011 
margens fluviais. Esse fato tem como consequência a supressão da mata ciliar, favorecendo a erosão e o assoreamento do leito desses rios que na região são os recursos hídricos de maior porte (Figura 4).

A análise da distribuição espacial das florestas do Município de Jaquirana levou à constatação de que no período compreendido entre os anos de 2002 e 2007 houve supressão da mata natural e intensificação da silvicultura, inclusive ao longo das margens dos rios da região.
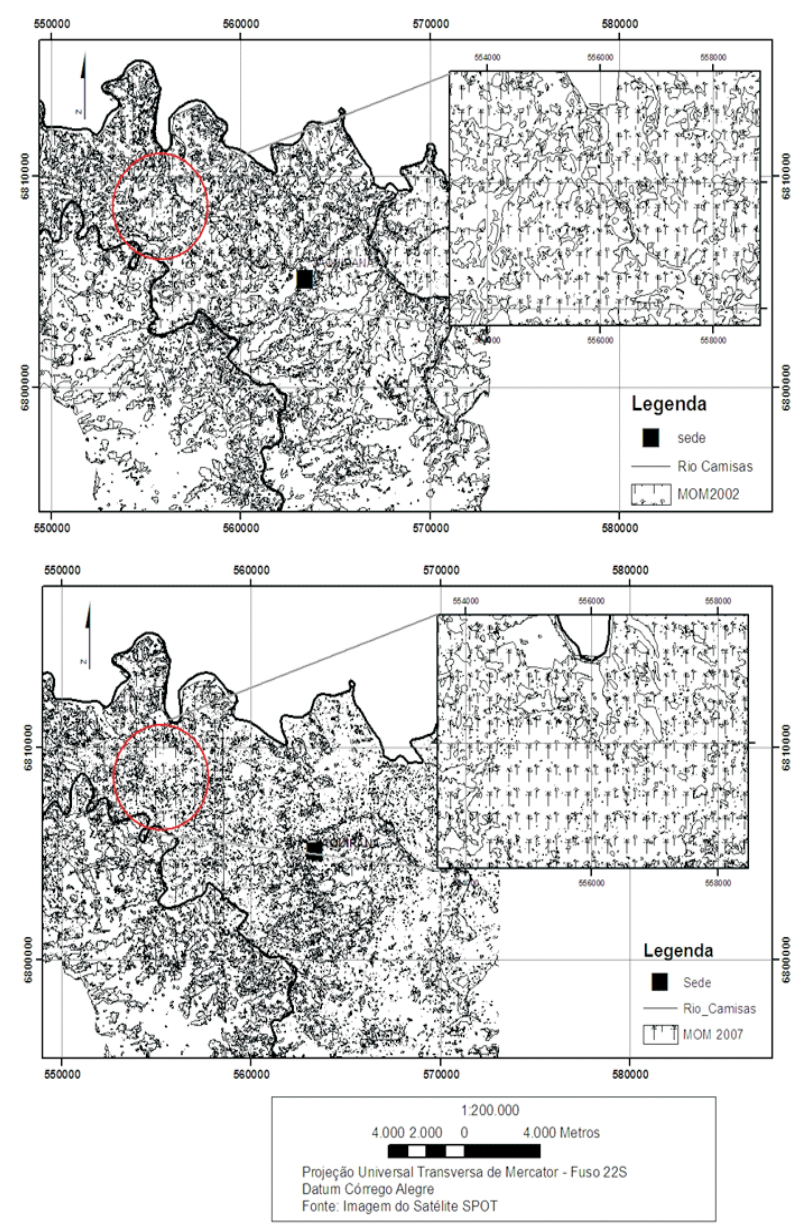

Figura 3 - Distribuição da Classe de Floresta Ombrófila Mista no Município de Jaquirana, nos anos de 2002 (acima) e 2007 (abaixo).

Figura 3 - Distribution of Mixed Ombrofilous Forest Class in the municipality of Jaquirana from 2002 (above)to 2007 (below).

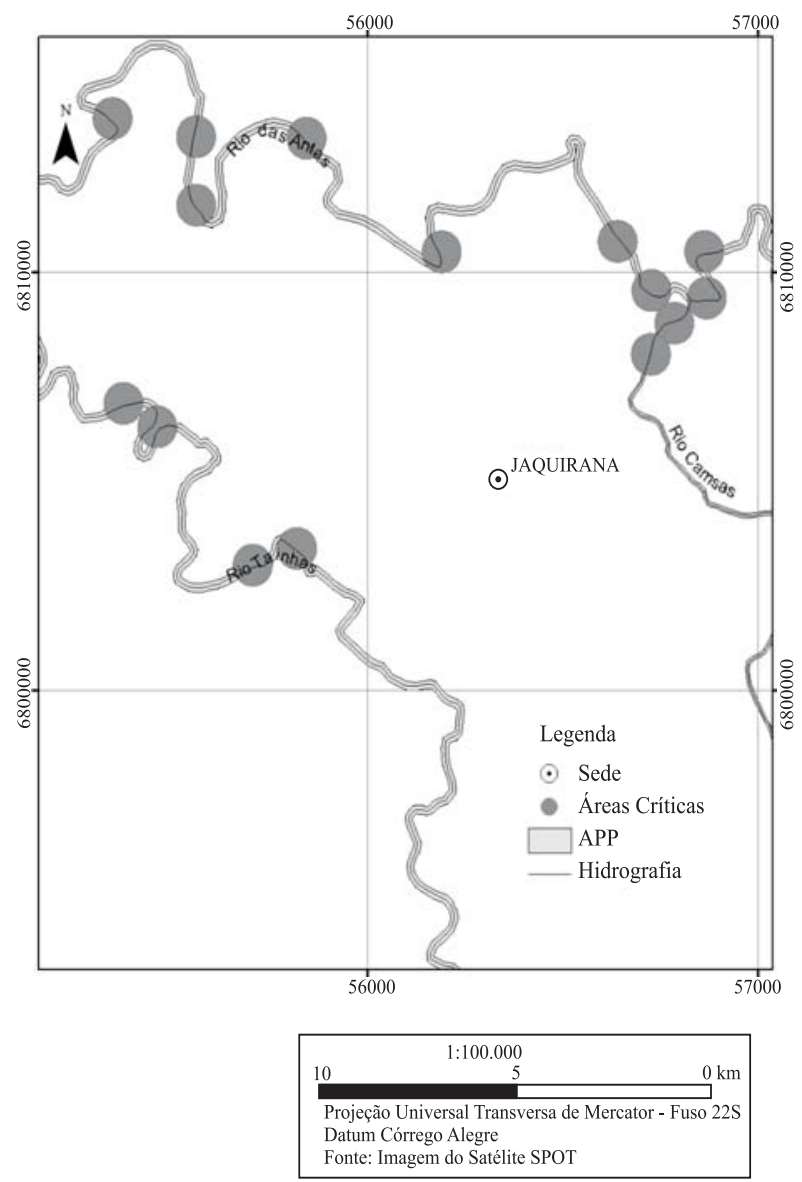

Figura 4 - Delimitação de áreas críticas em segmentos dos rios das Antas, Tainhas e Camisas.

Figure 4 -Delimitation of the critical areas in segments of the rivers Antas, Tainhas and Camisas.

No período avaliado, a Silvicultura (Figura 2) teve incremento de $422 \%$, enquanto a Floresta Ombrófila Mista (Figura 3), uma redução em área de 5.643,37 ha (Tabela 1), denotando intensificação no processo de fragmentação das florestas naturais, que pode trazer sérias consequências à manutenção dos ecossistemas.

Segundo Viana et al. (1992), a fragmentação florestal é um dos fenômenos mais marcantes e graves do processo de expansão da fronteira agrícola no Brasil, pois provoca o isolamento de manchas florestais de diferentes tamanhos, em meio a áreas alteradas. Essa fragmentação também impede o livre trânsito da fauna e a dispersão das sementes de espécies vegetais. 
Tabela 1 - Quantificação das classes de Silvicultura e de Floresta Ombrófila Mista no Município de Jaquirana nos anos de 2002 e 2007.

Table 1 - Quantification of the Silviculture and Ombrofilous Mixed Forest classes in the municipality of Jaquirana from 2002 to 2007.

\begin{tabular}{lcc}
\hline $\begin{array}{l}\text { Município de Jaquirana } \\
\begin{array}{l}\text { Área abrangida } \\
\text { pela imagem (em ha) }\end{array}\end{array}$ & $\begin{array}{c}\text { Ano 2002 } \\
\text { (em ha) }\end{array}$ & $\begin{array}{c}\text { Ano 2007 } \\
\text { (em ha) }\end{array}$ \\
\hline $\begin{array}{l}\text { Silvicultura (FL) } \\
\text { Área de Incremento }\end{array}$ & 921,10 & $4.814,37$ \\
Flor.Omb.Mista (MOM) & \multicolumn{2}{c}{$3.893,63$} \\
Área Suprimida & $5.643,37$ & $14.853,68$ \\
\hline
\end{tabular}

Outra consequência causada pela fragmentação da floresta natural é o efeito de borda, principalmente no perímetro das matas onde a maior ação dos ventos e da luminosidade causa modificações na porção marginal desses fragmentos florestais, tanto na composição florística quanto na abundância relativa das espécies (FORMAN; GODRON, 1986; GREGGIO et al., 2009). No Município de Jaquirana, além dessas consequências, a prática continuada da silvicultura estimula a propagação natural de Pinus sp., que pelas suas características de planta invasora ocupa os domínios da Floresta Ombrófila Mista e dos poucos remanescentes da Mata Atlântica que ainda existem na região.

Ainda, o avanço dessa espécie exótica até a margem dos rios pode alterar a estrutura da mata ciliar nativa que, por força de lei, deve ser preservada. Sua supressão causa a erosão das margens e, por consequência, o assoreamento dos rios, alterando a qualidade da água e prejudicando a vida aquática.

Com relação à premissa de que a silvicultura pode aumentar o potencial de sequestro de $\mathrm{CO}_{2}$ da atmosfera, estudos feitos por Wiesmeier et al. (2009) em áreas com plantações de Pinus taeda de diferentes idades, na região dos Campos de Cima da Serra, mostraram que a decomposição da matéria orgânica residual nos solos dessas áreas, além de contribuir para a acidificação das camadas mais superficiais, reduzindo a disponibilidade e suprimento de nutrientes, diminui o potencial de sequestro de carbono. Guo e Gifford (2002), numa revisão da literatura sobre a influência do uso da terra no sequestro de carbono, relataram que as plantações de pinus tendem a reduzir o estoque de carbono no solo, porque suas raízes têm a propriedade de estimular a decomposição da liteira e da matéria orgânica, podendo reduzir a absorção deste elemento em até 12 a 15\%. Argumentaram ainda esses autores que, quando a floresta nativa é consorciada com a silvicultura, o estoque de carbono não é afetado se as espécies vegetais nativas forem de folhas largas e ocorrerem em áreas de baixo índice pluviométrico.

Essa situação se modifica em regiões onde o índice excede os 1.500 mm/ano. Segundo Nimer (1990), é na borda da escarpa do Planalto das Araucárias que ocorre o mais alto índice pluviométrico da Região Sul (2.500 mm/ano, aproximadamente). Além disso, os solos da área de estudo, por serem rasos, são mais suscetíveis à desestruturação e esterilização, o que pode intensificar o processo erosivo. Somado a isso, a aplicação de pesticidas, necessária em práticas de monoculturas, altera a flora microbiana, um dos componentes responsáveis pela fertilidade do solo.

Diante do exposto, percebe-se que a intensificação da silvicultura, com consequente aumento da fragmentação da Floresta Ombrófila Mista no Planalto das Araucárias, pode alterar significativamente a dinâmica dos sistemas florestais mistos. De acordo com Backes et al. (2005), as florestas da região do planalto Nordeste do Rio Grande do Sul, formadas por coníferas de clima temperado (estrato superior), consorciadas com espécies latifoliadas tropicais (estratos inferiores) são sistemas florísticos e estruturais heterogêneos, cuja complexidade apresenta estratégias que ampliam suas variáveis funcionais, alcançando, dessa maneira, maior eficiência em todos os processos.

\section{CONCLUSÃO}

O processamento de dados ambientais georreferenciados com o objetivo de visualizar, espacializar, armazenar, preprocessar, processar e aplicálos na análise espacial, mostrou-se eficiente para a delimitação das áreas ocupadas por mata natural e por silvicultura no Município de Jaquirana. A quantificação das classes de Floresta Ombrófila Mista (MOM) e de Florestamento (FL) sugeriram que a fragmentação da classe MOM se deu em função da expansão da silvicultura entre os anos de 2002 e 2007.

A prática continuada e extensiva da silvicultura em áreas originalmente ocupadas por sistemas florísticos complexos e heterogêneos pode resultar em: degradação das matas ciliares, com consequente instabilidade das

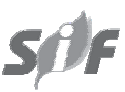

Revista Árvore, Viçosa-MG, v.35, n.4, p.867-873, 2011 
margens fluviais; contaminação dos aquíferos por pesticidas utilizados na silvicultura; e alteração da flora microbiana responsável pela fertilidade do solo pelo emprego de agrotóxicos, além da descaracterização da paisagem natural e da perda da biodiversidade.

O fato de a atividade madeireira, em suas diferentes fases de implantação, ser a principal atividade econômica e geradora de empregos no Planalto das Araucárias, não justifica o desequilíbrio ambiental causado pela prática da silvicultura em extensas áreas contínuas. A ocupação desmedida de espaços contendo restingas, lagoas, banhados, campos abertos e matas naturais, por reflorestamentos de uma única espécie, pode tornar essa singular região conhecida somente como aquela do "ouro verde e das primaveras silenciosas" (THEODORO, 2003), se medidas alternativas ao modelo vigente não forem implantadas pelos órgãos responsáveis pela preservação do meio ambiente.

\section{REFERÊNCIAS}

BACKES, A. et al. Produção de serapilheira em Floresta Ombrófila Mista, em São Francisco de Paula, Rio Grande do Sul, Brasil. Acta Botanica Brasileira, v.19, n.1, p.155-160, 2005.

FORMAN, R. T. T.; GODRON, M. Landscape ecology. New York: Wiley \& Sons, 1986.

GREGGIO, T. C. et al. Avaliação dos fragmentos florestais do município de Jaboticabal-SP. Revista Árvore, v.33, n.1, p.117-124, 2009.

GUASSELLI, L. A. et al. Identificação de remanescentes do bioma Mata Atlântica e análise temporal a partir de imagens SPOT, município de Gramado - Rio Grande do Sul. In: SIMPÓSIO BRASILEIRO DE SENSORIAMENTO REMOTO, 14., 2009, Natal. Anais... São José dos Campos: INPE, 2009. p.2745-2751. DVD, On-line. ISBN 97885-17-00044-7. Disponível em: <http://urlib.net/ dpi.inpe.br/sbsr@80/2008/11.17.17.55>.Acesso em: 07 jan. 2010.

GUO, L. B.; GIFFORD, R. M. Soil carbon stocks and land use change: a meta analysis. Global Change Biology, v.8, n.4, p.345-360, 2002.
INSTITUTO NACIONAL DE PESQUISAS ESPACIAIS - INPE. Fundação SOS Mata Atlântica. Atlas dos Remanescentes Florestais da Mata Atlântica - Período 2000 a 2005.

Disponível em:<http://mapas.sosma.org.br/ site_media/ATLAS\%20MATA\%20ATLANTICA\%20\%20RELATORIO2000-2005.pdf > . Acesso em 02. nov. de 2008.

MARCUZZO, S.; PAJÉ, S. M.; CHIAPPETTI, M. I. S. A reserva da biosfera da Mata Atlântica no Rio Grande do Sul: situação atual, ações e perspectivas. Porto Alegre: Conselho Nacional da Reserva da Biosfera da ata Atlântica, 1998. 60p. (Caderno, 11)

METZGER, J. P. Estrutura da paisagem: o uso adequado de métricas. In: CULLEN JUNIOR, L.; PÁDUA, C. V.; RUDRAN, R. Métodos de estudos em biologia da conservação e manejo da vida silvestre. Curitiba: Universidade Federal do Paraná/Fundação O Boticário de Proteção à Natureza, 2003. p.539-553.

NIMER, E. Clima. In: FUNDAÇÃO INSTITUTO BRASILEIRO DE GEOGRAFIA E ESTATÍSTICA IBGE. Geografia do Brasil: Região Sul. Rio de Janeiro: 1990. 422p.

ROISENBERG, A.; VIERO, A. P. O vulcanismo Mesozóico da Bacia do Paraná no Rio Grande do Sul. In: HOLZ, M.; DE ROS, L. F. (Org.). Geologia do Rio Grande do Sul. 2.ed. Porto Alegre: Universidade Federal Rio Grande do Sul, 2000. v.1. p.355-374.

SALDANHA, D. L et al. Monitoramento do impacto na vegetação da área de abrangência do PCMA-RS. Geração de mapas de uso, cobertura e dinâmica do solo. Porto Alegre: Centro Estadual de Pesquisas em Sensoriamento Remoto e Meteorologia CEPRSM/ UFRGS, 2008. 157p. (Relatório Técnico).

SOUZA, S. F. et al. Curso ArcView 9.0 -Módulo Básico. 3.ed. Porto Alegre: Laboratório de Geodésia - LAGEO, Instituto de Geociências, Universidade Federal do Rio Grande do Sul, 2006. 47p.

THEODORO, S. C. H. Ouro verde e as primaveras silenciosas da serra gaúcha. In: ENCONTRO NACIONAL DE ECONOMIA ECOLÓGICA, 5., 2003, Caxias do Sul. Anais... São Paulo: ECOECO, 2003. v.1. p.1-20. 
VIANA, V. M. et al. Restauração e manejo de fragmentos florestais. In: CONGRESSO NACIONAL SOBRE ESSÊNCIAS NATIVAS, 2., 1992, São Paulo. Conservação da biodiversidade. Anais... São Paulo: Instituto Florestal, 1992. p.400-406.
WIESMEIER, M. et al. Depletion of soil organic carbon and nitrogen under Pinus taeda plantations in Southern Brazilian grasslands (Campos). European Journal of Soil Science, v.60, p.347-359, 2009. 
